SHORT REPORT

\title{
Nine cases of accidental exposure to dimethyl sulphate-a potential chemical weapon
}

\section{J C R Rippey, M I Stallwood}

Emerg Med J 2005;22:878-879. doi: 10.1136/emj.2004.015800

Dimethyl sulphate (DMS) is an innocuous appearing, widely used, and highly toxic chemical. It is used both as a methylating agent in industrial chemical synthesis and in medical laboratories for chemical cleavage of DNA. It is readily absorbed through the skin, mucous membranes, and gastrointestinal tract. Delayed toxicity allows potentially fatal exposures to occur prior to development of any warning symptoms. Toxicity is manifested initially by mucosal inflammation of eyes, nose, oropharynx, and airways. This can progress to severe airway oedema and necrosis, and non-cardiogenic pulmonary oedema. Other systemic effects include convulsions, delirium, coma, and renal, hepatic, and cardiac failure. All these features make DMS a potential chemical weapon.

We report nine cases of varying degrees of inhalational exposure to DMS, occurring as a result of a single chemical spillage incident in the United Kingdom. Industrial poisoning is surprisingly rare and there are few previous reports in the literature outside China.

$\mathrm{D}$ methyl sulphate $\left(\mathrm{CH}_{3}\right)_{2} \mathrm{SO}_{4}$ (DMS) is a methylating agent used industrially in the synthesis of pharmaceuticals, dyestuffs, perfumes, and pesticides. ${ }^{1}$ It is also used medically for chemical cleavage of DNA sequences. DMS is highly toxic, corrosive, and has carcinogenic, mutagenic, and teratogenic potential. ${ }^{34}$ It is an oily, clear, colourless, or pale yellow fluid with a faint onion like odour." It's vapour density is $4.35($ air $=1)$. The melting point is $-32^{\circ} \mathrm{C}$; the boiling point is $188^{\circ} \mathrm{C}$. At $20^{\circ} \mathrm{C}$ the vapour pressure is $0.5 \mathrm{mmHg} .{ }^{6}$

Absorption occurs readily through the skin, mucous membranes, and gastrointestinal tract. After acute exposure, symptoms are usually delayed for several hours, allowing potentially fatal exposures to occur before the patient becomes aware of their plight. ${ }^{378}$ DMS hydrolyses slowly into sulphuric acid, methyl hydrogen sulphate, and methanol on contact with mucosal surfaces. Sulphuric acid and methyl hydrogen sulphate are highly irritative and corrosive to these surfaces. The methanol may be absorbed into the circulation causing neurotoxicity. ${ }^{1}$ DMS is also a potent methylating agent for cellular macromolecules, including DNA. ${ }^{9}{ }^{10}$ It has been classified a probable human carcinogen (group 2A) by the International Agency for Research on Cancer. ${ }^{10}{ }^{11}$ Chronic low level occupational exposure has recently been reported in chemical plant workers and the major concern in this group is potential carcinogenicity. ${ }^{10}$

The innocuous appearance and delayed toxicity of DMS led the United States military to use it as the theoretical chemical weapon in a recent large scale terrorist attack training exercise. ${ }^{7}$ The Germans first experimented with DMS as a potential warfare agent during World War I because of its powerful vesicant properties.

\section{CASE REPORTS}

The exposure occurred in an industrial hose manufacture and repair plant in August 2003. Three male workers aged 28-32 years were in a $12 \times 12 \times 4$ metre workshop wearing overalls, boots, and gloves, but no other protective gear. The workshop had open doorways leading into rooms containing another six people. The environmental temperature was $24.6^{\circ} \mathrm{C}$ outdoors $^{12}$ and the workshop contained a working fan.

A short length of enclosed industrial hose had been sent from another company for repair. On opening the hose, about $125 \mathrm{ml}$ of clear liquid spilled onto the concrete floor without making skin contact with the workers. Assuming the fluid was water the men initially ignored it. Two workers left the workshop for adjacent rooms after two and three minutes, respectively. The third man (patient 1) considered the possibility of a chemical spill and used a high pressure water hose to dilute the liquid.

Thirty to sixty minutes after exposure all three workers noted eye irritation with discomfort, lacrimation, and erythema. The supplying company was contacted and confirmed the hose had been filled with DMS. Patient 1 then poured sand onto the diluted DMS, sealed the contaminated sand in a bin, and washed the floor down again. He remained with the uncontained DMS for approximately one hour. The other workers remained in adjacent rooms during this period. All three briefly irrigated their eyes with saline.

Five hours after exposure, the three workers presented to hospital with DMS safety data sheets. ${ }^{6}$ All three had marked conjunctival injection, lacrimation, rhinorrhoea, and a burning foreign body ocular sensation; symptoms were most marked in the patient most exposed to DMS (patient 1).

Although further advice was sought from a national poisons information centre the men had their eyes irrigated with normal saline. Slit lamp examination revealed marked conjunctival injection and punctuate corneal erosions. These were most marked in patient 1 , who also complained of clouding of his vision. Acuity testing was normal, and all patients were commenced on topical chloramphenicol.

All three were showered, put into hospital gowns, and admitted for observation for possible development of delayed non-cardiogenic pulmonary oedema.

At nine hours, patient 1 had developed increasing throat tightness, hoarseness, a persistent harsh croup like cough producing clear sputum, excessive salivation, chest tightness, and subjective dyspnoea. Patient 2 had developed epistaxis and also complained of a sore tight throat.

Under local anaesthesia, fibreoptic laryngoscopy was performed on patient 1 . It revealed marked erythema of the false cords and arytenoids with a degree of laryngeal oedema but a reasonable laryngeal inlet. It was decided to preemptively intubate this patient as it was uncertain how his upper airway injury would progress.

Abbreviation: DMS, dimethyl sulphate 
A mild transient neutrophilia, lymphopenia, and monocytopenia were noted, as well as a transient isolated elevation in serum bilirubin to $49 \mu \mathrm{mol} / \mathrm{l}$ (normal range $2-17 \mu \mathrm{mol} / \mathrm{l}$ ). Other blood tests, chest radiograph, and an electrocardiogram were all normal.

Intravenous dexamethasone $8 \mathrm{mg} \quad(0.1 \mathrm{mg} / \mathrm{kg})$ eight hourly was commenced. Gas exchange remained satisfactory overnight and he was extubated the following day. His chest tightness had resolved, but rhinorrhoea persisted for 72 hours after extubation. A cough productive of clear sputum persisted for three weeks, occasionally accompanied by wheezing. His visual blurring and discomfort cleared by day four and the conjunctival injection resolved completely by two weeks. Patient 1 returned to his normal work and exercise regime four weeks later. On follow up at three months the patient was entirely asymptomatic.

Patient 2 had normal observations with no hoarseness or stridor on repeat examination. His epistaxis was minor and resolved spontaneously. His progress was uneventful and he was discharged the following day. He noted nasal stuffiness, mild throat discomfort, and increased salivation for three days. His eye discomfort settled within 48 hours, and the erythema resolving after two weeks.

Patient 3 was discharged after overnight observation. His eye discomfort and rhinorrhoea settled within 24 hours, and the conjunctival erythema resolving by one week.

Six people working in the building did not enter the room where the spill occurred. Five of these developed symptoms, four presenting to hospital the following day. They all had mild conjunctival injection; two had a few punctuate epithelial erosions. One also described slight nasal symptoms and another mild throat irritation.

\section{DISCUSSION}

The toxicity of DMS, coupled with its availability, innocuous appearance, and delayed onset of potentially fatal symptoms make it a potential chemical agent of terrorism of which emergency physicians should be aware.

These cases demonstrate the characteristic delay in symptom onset previously reported in the literature. The patients who were most exposed to DMS developed symptoms of toxicity more quickly, and their symptoms were worse and longer lasting. The mucous membrane injury initially developing in the eyes and then progressing to nasal and upper airway symptoms is characteristic. The raised white cell count is also characteristic. Fortunately none of our cases developed the severe laryngeal oedema, non-cardiogenic pulmonary oedema, toxic shock, encephalopathy, myocardial damage, or methanol toxicity that can occur with greater exposures.

General treatment of DMS toxicity involves minimising exposure of patients and decontamination, together with close observation and supportive management. If there are manifestations of neurotoxicity one should evaluate for and treat possible associated methanol toxicity. Early high dose steroids are thought to reduce lung toxicity, decreasing the incidence and severity of non-cardiogenic pulmonary oedema. $^{513}$

\section{ACKNOWLEDGEMENTS}

The authors would like to thank Professor Virginia Murray, Director of the Chemical Hazards and Poisons Division (London), for her valuable assistance in the management of this incident.

\section{Authors' affiliations}

J C R Rippey, Emergency Physician, Royal Liverpool University Hospital, Prescot Street, Liverpool, L7 8XP, United Kingdom

M I Stallwood, Clinical Fellow in Intensive Care Medicine, Intensive Therapy Unit, Royal Liverpool University Hospital, United Kingdom

Competing interests: none declared

Correspondence to: James Charles Rowland Rippey, Emergency Physician, Royal Liverpool University Hospital, Prescot Street, Liverpool, L7 8XP, United Kingdom; James.Rippey@rlbuht.nhs.uk or j.rippey@ btopenworld.com

Accepted for publication 25 September 2004

\section{REFERENCES}

1 Ellenhorn MJ. The hydrocarbon products. In: Ellenhorn MJ, eds. Ellenhorn's Medical Toxicology: Diagnosis and Treatment of Human Poisoning. $2^{\text {nd }}$ ed. Baltimore: Williams and Wilkins, 1997:1427-9.

2 Cartwright IL, Kelly SE. Probing the nature of chromosomal DNA protein content by in vivo footprinting. Biotechniques 1991;11:188-90.

3 Vyskocil A. Dimethyl sulphate: review of toxicity. Central Eur J Occup Environ Med 1999:5:72-82.

4 U. S. Environmental Protection Agency: Integrated Risk Information System (IRIS) on Dimethyl Sulfate (CASRN 77-78-1). Available at http:// www.epa.gov/iris/subst/0365.htm (accessed 02 September 2003).

5 Wang $Y$, Xia J, Wang Q. Clinical report on 62 cases of acute dimethyl sulfate intoxication. Am J Ind Med 1988;13:455-62.

6 Whyte Chemicals Limited Safety Data Sheet. Product Name Dimethyl Sulphate; CAS-No 77-78-1; EC no 201-058-1; Product Code D070; Issue date 23.07. 2002 Ref: D070/V5/, 2002:1-5.

7 Siegel D, Younggren BN, Ness B, et al. Operation castle cascade: managing multiple casualties from a simulated chemical weapons attack. Military Medicine 2003;168(5):351-4.

8 POSINDEX ${ }^{\circledR}$ Information System, Micromedex Inc. 2002 (Via National Poisons Information Service, Guys Hospital, London).

9 Mathison BH, Taylor ML, Bogdanffy MS. Dimethyl sulfate uptake and methylation of DNA in rat respiratory tissues following acute inhalation. Fundam Appl Toxicol 1995;28(2):255-63.

10 Schettgen T, Broding HC, Angerer J, et al. Dimethyl sulphate; a hidden problem in occupational medicine. Occup Environ Med 2004;61(1):73-5.

11 IARC. Dimethyl Sulphate. IARC Monograph Eval Carcinog Risks Hum 1999:71:575-89.

12 Met Office data. FitzRoy Rd, Exeter, Devon, EX1 3PB, United Kingdom.

13 Ip $\mathrm{M}$, Wong KL, Wong KF, et al. Lung injury in dimethyl sulfate poisoning. 